\title{
On the dependence of HIFU temperature on size and concentration of silicon microparticles
}

\author{
[JC.Melgarejo; P.Candelas; C. Rubio; I.Rodriguez; E.Sánchez; A.Uris]
}

\begin{abstract}
For a decade, silicon microparticles have attracted the attention of the scientific community. Currently, a large number of scientific advances are based on the use of microparticles as acting surfaces, vehicles, information systems, new materials or in biomedicine. This report focuses on increasing the efficiency of the High Intensity Focused Ultrasound technique (HIFU) by using silicon microparticles, which are characterized by their good biocompatibility, the easy obtention in different sizes and shapes, as well as the easy functionalization.
\end{abstract}

Keywords-HIFU, ultrasounds, silicon microparticles, temperature

\section{Introduction}

Cancer is one of the principal causes of death in advanced societies, in particular, in Spain 210.000 people are diagnosed with cancer every year [1]. Almost $50 \%$ of deaths in middle-aged people are caused by this pathology [2]. These facts justifiy the importance of research on this field.

Technological advances have made possible the developement of new devices, techniques and medical procedures, establishing as a group of therapies called minimmally invasive or interventionists, allowing in some cases to replace complex surgical interventions and to complement pharmacological treatments with non aggressive procedures for the patient, increasing the efficiency of the treatment.

In this group of minimmally invasive techniques are High Intensity Focussed Ultrsound (HIFU), which allow tumor ablation without a surgical intervention.

At this moment, the most developed HIFU applications are the treatment for solid benign tumors such as the benign prostate hyperplasia and benign tumors of uterus and breasts. Between the oncological applications, treatments for primary and secundary cancerous tumors of liver, breasts, kidney, pancreas, soft tissue and bone sarcoma and retroperitoneal tumours are found $[3,4]$.

HIFU treatment consists in focussing a high frequency ultrasound beam in a small tissue volume (figure 1).

Ultrasound passes safely through soft tissue, with enough energy to locally destroy the tissue in which its beam is focussed. The two mechanisim of ablation are the direct increasemnet due to energy accumulation in the focal point and cavitation. The first one inmediately induces coagulative necrosis in the tissue, when exposed to temperatures between 60 and 100 degrees for a second. The temperature increase depends on the tissue absortion coefficient, shape and the temperature sensitivity of the affected area. Biological changes depends on the time and level of exposure. A thermal dose that exceedes a certain threshold causes tissue coagulation and conducts an irreversible cell damage [4], as shown in figure 2.
The other physical phenomenon is cavitation, produced when intracellular microbubbles resonate with the high intensity ultrasound waves, destroying the tumor.

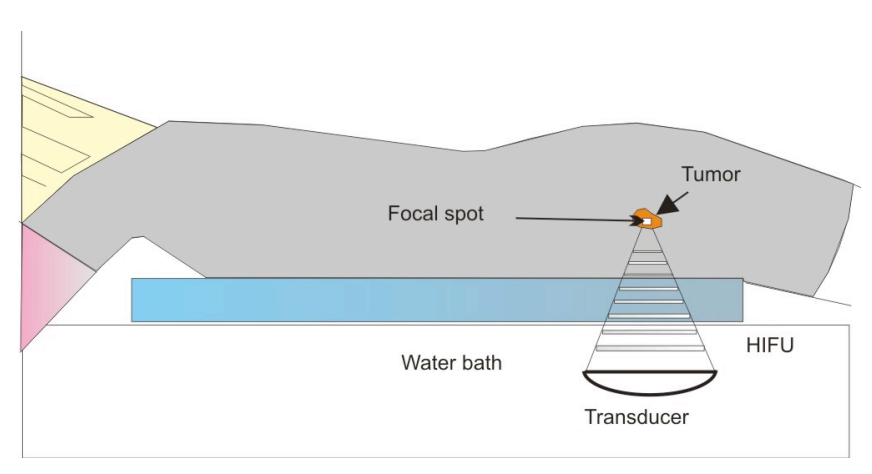

Figure 1: HIFU technique for tumor ablation

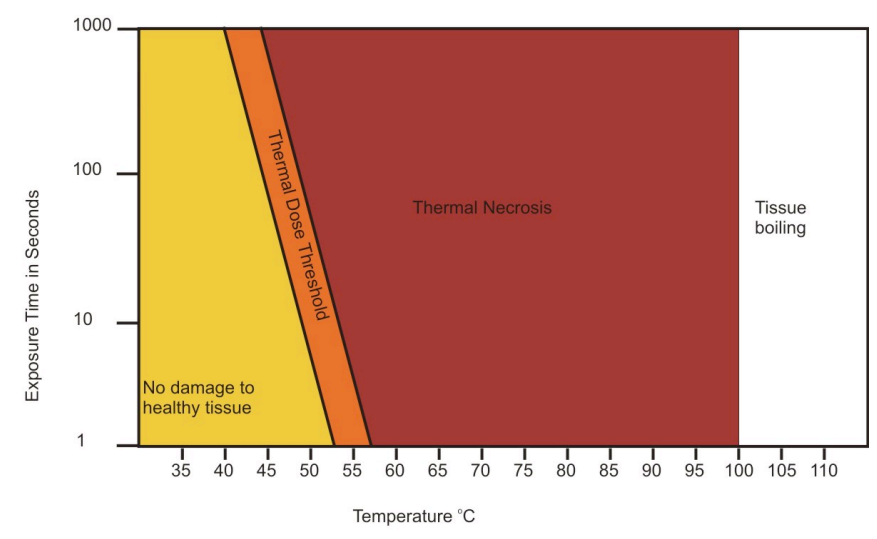

Figure 2: Tissue damage

This paper studies the influence of silicon microparticles in the increase of temperature.

\section{Experimental Setup}

Two types of mesures have been takes upon agar samples with different sizes and concentrations of silicon microparticles. The agar samples were obtained heating 500 $\mathrm{ml}$ of distilled water with $30 \mathrm{ml}$ of agar (6\% solution).

The used microparticles were obtained from different manufactures: the $2 \mu \mathrm{m}$ diameter come from ECUTEC, the $75 \mu \mathrm{m}$ from SILGRAIN, and the $100 \mu \mathrm{m}$ from FA.

In a typical procedure, $400 \mathrm{mg}$ of Agar-agar (Algamar) were delayed in $30 \mathrm{ml}$ of distillated water in a beaker equipped with a stirring bar, and the mixture was heated to $100^{\circ} \mathrm{C}$ with a hot plate and degas for $10 \mathrm{~min}$. Silicon microparticles were mixed with $10 \mathrm{~mL}$ of distillated water and $10 \mathrm{ml}$ of surfactant (Triton X 100, Panreac), and sonicated for $10 \mathrm{~min}$ in an ultrasonic bath. Silicon microparticles suspension was 
poured into the Agar-agar solution and the mixture was heated on the magnetic stirring plate for $5 \mathrm{~min}$.

The beaker was then removed from the hot plate and was maintained under stirring until the mixture has cooled to a warm temperature. Then the solution of silicon microparticles in Agar-agar was transferred into a $50 \mathrm{ml}$ bottle containing a both sides open PVC pipe of $2 \mathrm{~cm}$ of diameter, with 2 holes previously drilled for sensor temperature. The bottle was immediately plunged into liquid nitrogen for $10 \mathrm{~s}$, and left at $4^{\circ} \mathrm{C}$ for $2-4 \mathrm{~h}$ for complete solidification. Agar-agar/Silicon composite was removed from the bottle and the sample casted into PVC pipe was employed for ultrasound experiments. The figure 3 shows the silicon microparticles used.

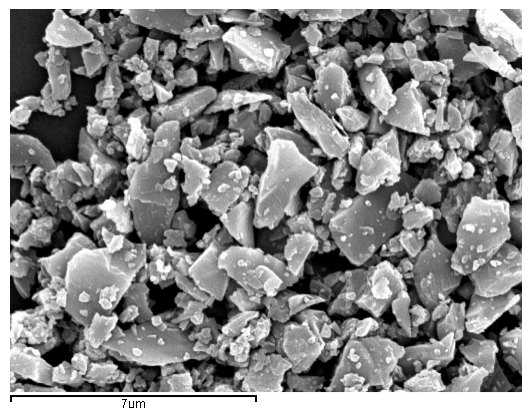

Figure 3: TEM image of Si microparticles.

The studied concentrations were $8 \mathrm{~g} / 1$ (2 grams of $\mathrm{Si}$ in $250 \mathrm{ml}$ of agar) and $40 \mathrm{~g} / \mathrm{l}$ (10 grams of $\mathrm{Si}$ in $250 \mathrm{ml}$ of agar). In order to calculate the ultrasound propagation speed in the samples, a Panametrics 5072PR Pulser-Receiver was used as the ultrasound source, two Olympus $3.5 \mathrm{MHz}$ transducers and a Tektronix TDS1002B osciloscope was used to represent the signals.

Direct transmission measures were made trough an $11 \mathrm{~mm}$ diameter cylinder $34.3 \mathrm{~mm}$ long, obtaining for each case the resulting $3.5 \mathrm{MHz}$ pulse, and calculating the ultrasound speech as the divison of the distance of the transducers and the pulse's time of flight.

Besides, temperature measures have been taken using a $\mathrm{K}$ termocouple, with the Cobra 4 acquisition system (figure 4).
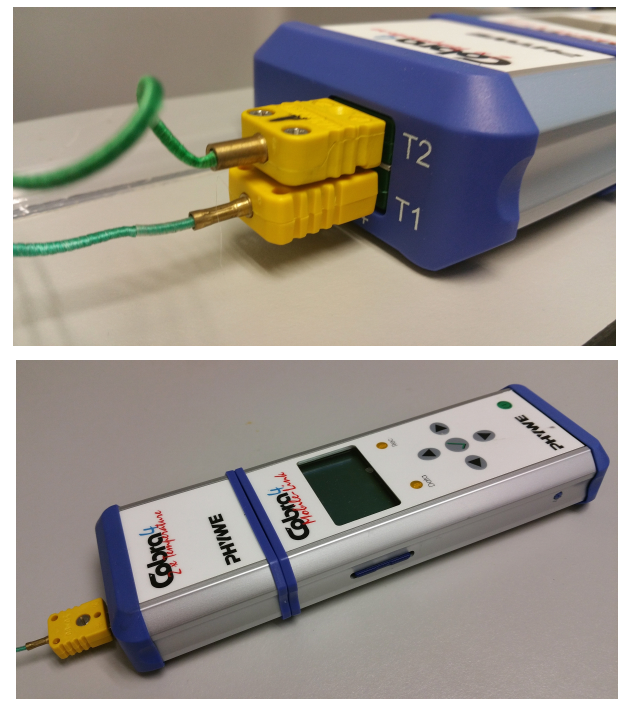

Figure 4: (a) Type K thermocouple, (b) Acquisition system Cobra 4
In order to measure the temperature, $23 \mathrm{~mm}$ diameter cylindrical samples $30 \mathrm{~mm}$ long contained in PVC holder were used as shown in figure 5. A type $\mathrm{K}$ thermocouple was introduced in the focal region, which then registers temperature rise due to the sonicaction of high intensity ultrasound produced by the $3.5 \mathrm{MHz}$ SU-102 Sonic Concepts's transducer. Data was recorded for 60 seconds, in which the transducer was acting for 30 seconds.

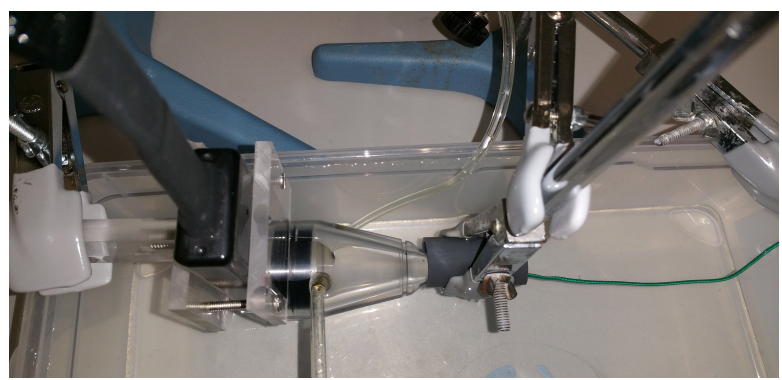

Figure 5: Experimental setup.

\section{Results and discussion}

In the first place, the agar samples were characterized without the presence of microparticles and a $1429.13 \mathrm{~m} / \mathrm{s}$ propagation speed was measured. When the silicon microparticles were added to the samples, a decrease in the ultrasound propagation speed was observed, depending on the size and concentration of the particles. The results are shown in the following tale:

\begin{tabular}{|c|c|c|c|}
\hline & \multicolumn{3}{|c|}{ Microparticles diameter $(\boldsymbol{\mu m})$} \\
\hline$(\mathrm{g} / \mathrm{l})$ & 2 & 75 & 100 \\
\hline 8 & $\mathrm{v}=1395,44 \mathrm{~m} / \mathrm{s}$ & $\mathrm{v}=1401,14 \mathrm{~m} / \mathrm{s}$ & $\mathrm{v}=1426,78 \mathrm{~m} / \mathrm{s}$ \\
\hline 40 & $\mathrm{v}=1387,54 \mathrm{~m} / \mathrm{s}$ & $\mathrm{v}=1363,27 \mathrm{~m} / \mathrm{s}$ & $\mathrm{v}=1408,5 \mathrm{~m} / \mathrm{s}$ \\
\hline
\end{tabular}

According to the values of the table, the ultrasound propagation speed in every agar solution with microparticles is lower than the speed obtained with no particles. Besides, as the particles concentration increases, the temperature decreases. Therefore, the sound wave remains longer in the tissue, contributing to the temperature rise.

In the figure 6 , the graphic results of temperature for different concentrations are shown. It can be observed that when $40 \mathrm{~g} / 1$ concentration are used, higher temperature are reached in less time than when $8 \mathrm{~g} / 1$ are used, independently of the size of the silicon microparticle. 

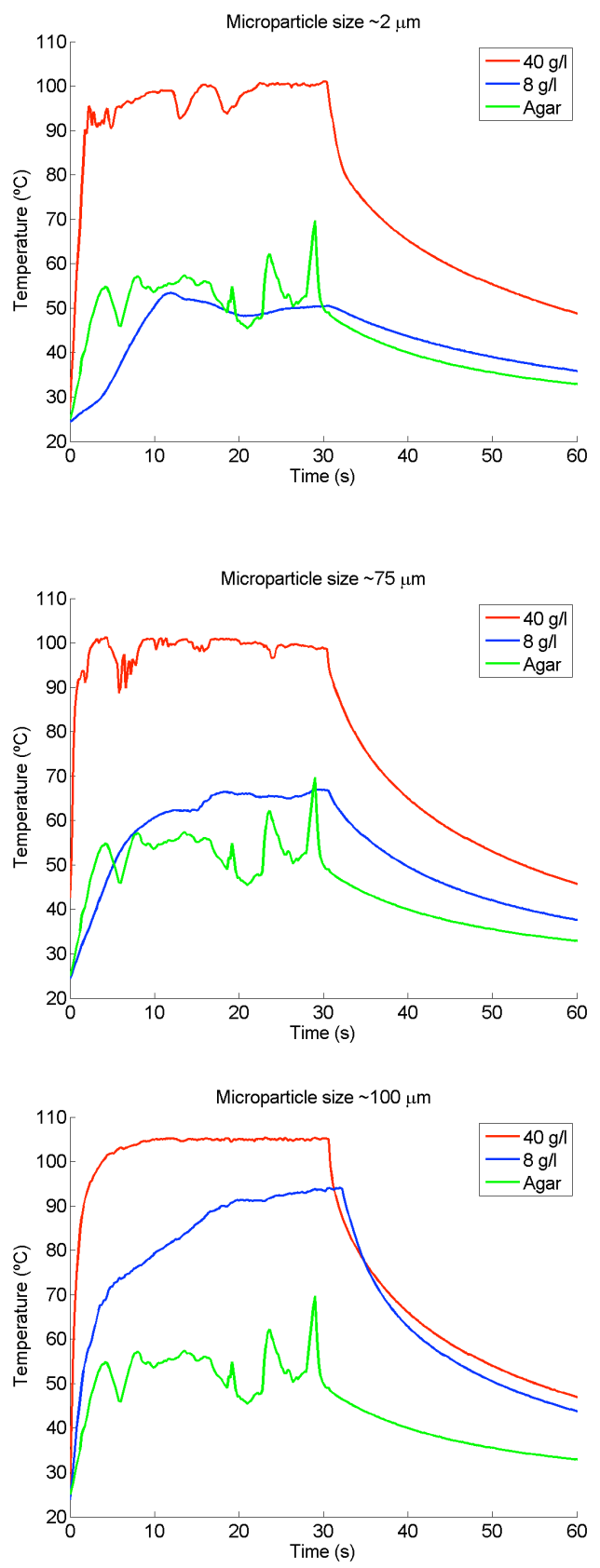

Figure 6: Temperature rise for (a) $2 \mu \mathrm{m}$ particles, (b) $75 \mu \mathrm{m}$ particles, (c) $100 \mu \mathrm{m}$ particles.

In the figure 7 we can see the temperature rise for the two concentrations. Independently of the particle size, for a 40 $\mathrm{g} / 1$ concentration temperatures higher than $95^{\circ} \mathrm{C}$ are reched in less than 2.5 seconds, whilst for a $8 \mathrm{~g} / 1$ concentration, the higher temperature reached is $59^{\circ} \mathrm{C}$ for the $100 \mu \mathrm{m}$ diameter particles and just $28^{\circ} \mathrm{C}$ for the $2 \mu \mathrm{m}$ diameter particles.

For a $40 \mathrm{~g} / \mathrm{l}$ concentration, the maximum reached temperature is around $100{ }^{\circ} \mathrm{C}$ for all sizes, whilst for a $8 \mathrm{~g} / 1$ concentration, the particle size is an influential factor, as for the $100 \mu \mathrm{m}$ diameter particles temperatures of $94^{\circ} \mathrm{C}$ are reached, while in the case of $2 \mu \mathrm{m}$ diameter particles, the maximum reached temperatured is of $53{ }^{\circ} \mathrm{C}$.
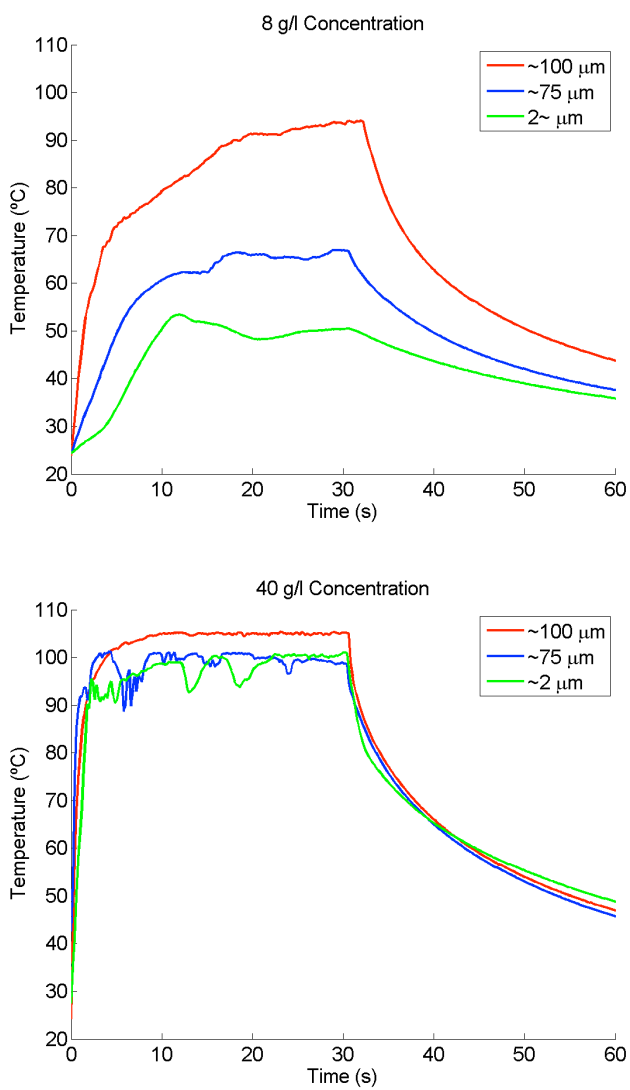

Figure 7: Temperature rise for (a) $8 \mathrm{~g} / 1$ concentration, (b) $40 \mathrm{~g} / \mathrm{l}$ concentration

As for the radiological images, there are clear differences between the samples with and wihout silicon microparticles (Figure 8).

Silicon microparticles increase the echogenicity of the sample, independently of the size and concentration of the microparticles. Because of its echogenicity, it is possible to distinguish the variations of the concentration of microparticles in the sample, as shown in figure 8 .

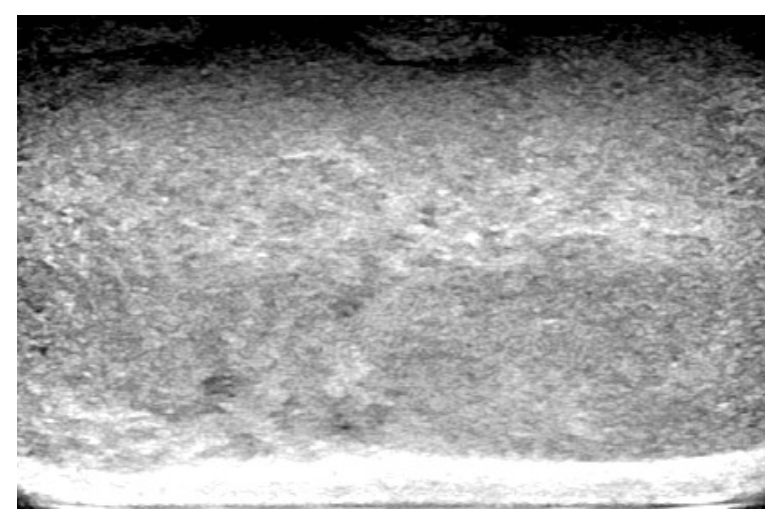

Figure 8: Ultrasound image with a $15 \mathrm{MHz}$ probe. Sample with $40 \mathrm{~g} / \mathrm{L}$ concentration of $100 \mu \mathrm{m}$ particles. 
JC.Melgarejo ${ }^{1}$; P.Candelas; C. Rubio; I.Rodriguez; A.Uris

Centro de Tecnologías Físicas, Universitat Politècnica de València

Spain

auris@,fis.upv.es

E.Sánchez

Hospital Francesc de Borja

Spain

\section{Conclusions}

The previous results suggest that, despite the fact that when adding silicon particles to an agar solution the ultrasound propagation speech decreases, and the energy remains more time inside the sample contributing to increase its temperature, this is not the principal cause. In that case, there would be a direct relation between the propagation speed and the reached temperature. In this paper, and due to the possibility of bubble formation within the preparation of the samples, it is possible that other mechanism such as cavitation are actively contributing to the heating.

It has been confirmed that for high enough concentrations, independently the size of the particles used, the temperature reaches $95^{\circ} \mathrm{C}$, which is much greater than the $55^{\circ} \mathrm{C}$ reached in agar. It should also be pointed out that in presence of silicon microparticles, the maximum temperature is reached within three seconds.

In this paper, it has been demonstrated that it is possible to reach high temperatures with $2 \mu \mathrm{m}$ particles when applying the right dose, so it would be of interest to study the behaviour of silicon nanoparticles as well.

\section{Acknowledgment}

This work is supported by grant GVA- AICO/2015/119. The advise work from the Institute of Cancer Research is gratefully acknowledged.

\section{References}

[1] [1] J.J.Cruz, presidente de la Sociedad Española de Oncología Médica (SEOM). XIV Congreso Nacional SEOM, Salamanca 2013.

[2] [2] Karim-Kos HE de VE, Soerjomataram I, Lemmens V, Siesling S, Coebergh JW. Eur J Cancer; 44(10):1345-89 (2008)

[3] [3] Kennedy J. Nat Rev Cancer; 5:321-7 (2005)

[4] [4] Kennedy JE, Ter Haar GR, Cranston D. Br J Radiol; 76(909):5909 (2003)

[5] [5] CC Coussios, $\mathrm{CH}$ Farny et al. International Journal of Hyperthermia 23 (2), 105-120 (2007)

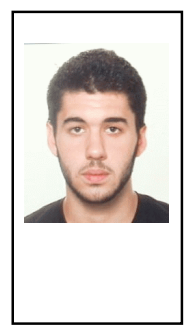

Juan Carlos Melgarejo received his bachelor's degree in electrical engineering from the Universitat Politècnica de València (Spain) in 2015. He is currently studying his MS and researching with the ETSIT's physics department in the field of ultrasounds.

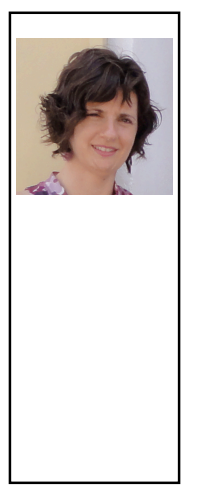

\begin{tabular}{|} 
Pilar Candelas studied \\
Telecommunications Engineering at the \\
Universitat Politècnica de València \\
(Spain) and completed her PhD in 2003 in \\
the field of ultrasounds. Currently, she is \\
an assistant professor in the \\
E.T.S.I.Telecomunicación at the \\
Universitat Politècnica de València and \\
her research has been developed in the \\
area of Applied Acoustics, particularly in \\
Biomedical Ultrasounds
\end{tabular}

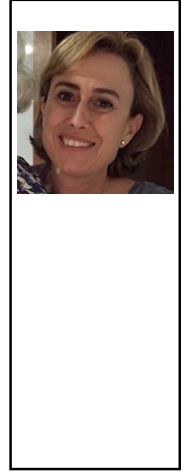

Constanza Rubio is an assistant professor at the Universitat Politècnica de València since 1996. Her research line has been developed in the area of Applied

Acoustics, particularly in the

Environmental Acoustics. Her publications have appeared deserved reviews in New Scientist Magazine, Science Update electronic edition of Nature as well as in other more general character media.

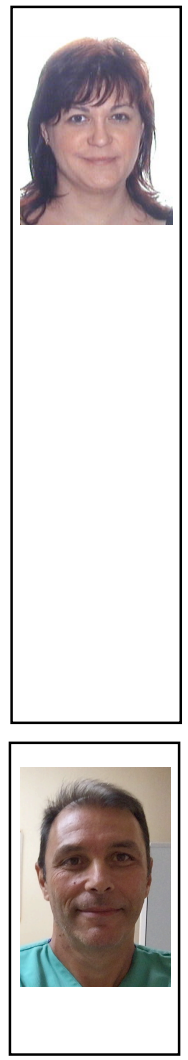

Isabelle Rodriguez studied Chemistry at the Science and Technology University of Languedoc in Montpellier (France) and completed her $\mathrm{PhD}$ in 1995 at the National Graduate School of Chemistry of Montpellier (ENSCM) in the field of heterogeneous catalysis. She did a postdoctoral fellowship from 1997 to 2001 at the Institute of Chemical Technology (ITQ) at the Polytechnic University of Valencia under the supervision of Prof. Avelino Corma. Currently, she is mainly involved in the study of Silicon microparticles, their preparation and optical properties, as well as in their technological applications including in therapeutic and biomedical field.

Eugenio Sánchez received a bachelor in medicine and surgery from the University of Valencia (Spain). He obtained his Radiologists specialization at $\mathrm{La} \mathrm{Fe}$ Hostipal. Now he is Head Service of the Francesc de Borja Hospital of Gandia (Valencia).

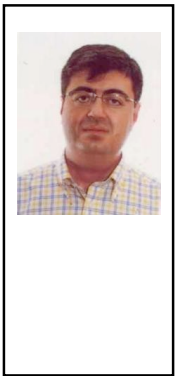

Antonio Uris studied Mechanical

Engineering at the Universitat Politècnica de València (Spain) and completed his

$\mathrm{PhD}$ in 1998 in the field of airborne sound isolation. Currently, he is an assistant professor in the E.T.S.I.Telecomunicación at the UPV. Nowadays he is involved in the study of ultrasonic lens. 